\title{
Increase In Electrical And Thermal Conductivities Of Doped Polymers Dependent On Their Intrinsic Properties; Case Study: Polymers [Polystyrene, Polyethylene, Poly Propylene, Nylon66,] Doped With Graphite.
}

\author{
* Uleanya Kelechi Ogochukwu ${ }^{1}$, Eboatu Augustine Nnarue ${ }^{2}$ \\ ${ }^{I}$ Chemistry Programme, School of Science and Technology, National Open University of Nigeria, 14/16 \\ Ahmadu Bello Way, P.M.B. 80067 Victoria Island, Lagos, Nigeria \\ ${ }^{2}$ Department of Industrial Chemistry Faculty of Natural Sciences Nnamdi Azikiwe University, P.M.B. 5025 \\ Awka, Anambra State Nigeria
}

\begin{abstract}
Most Polymers do not possess natural intrinsic properties that will be enough for them to be used as semi- conductors. In the world trend of industrial growth where polymers seem to be replacing all semi-conductors because of their availability, durability, recyclability and reduced cost, attention is being strongly given to their improvement them for this essential function hence the need for this research.Eight samples each of four polymers; polyethylene (PE), polystyrene (PS), poly propylene $(P P)$,nylon 66 were prepared by doping with different concentrationsof graphite to enhance their electrical and thermal conductivities, considering the fact that they are of different intrinsic properties. The samples were testedfor their electrical and thermal conductivities.It was evident that as the concentration of the graphite dopantincreases, the electrical and thermal conductivities of all the polymers increased although not at the same rate.The most interesting fact is that all polymers that showed highly favorable results in electrical conductivity, showed the least for thermal conductivities which can be attributed to their intrinsic properties.
\end{abstract}

Key words: polymers, doping, graphite, thermal conductivities, electrical conductivities.

\section{Introduction}

Conductive polymers are organic polymers that possess electrical, electronic, magnetic, and optical properties of a metal while retaining mechanical properties processibility commonly associated with a conventional polymer ${ }^{[1]}$. It can also be defined as any system that contains an additive to lower resistivity. Theresistivity of unmodified polymers or plastics is $1016 \Omega \mathrm{m}$ while conductive additives can lower resistivity level in steps down to $104 \Omega \mathrm{m}$ resistivity range ${ }^{[2]}$. This work is focused primarily on the enhancement of their crucial properties:electrical and thermal conductivities that are required of a polymer for it to be accepted for all good uses especially as a semiconductor. Commonly discarded polymers and materials from the environment were used as a means of waste control. Cost management was considered since tailor- made conductive polymers are very costly and this has served as a strong limitation for their use.These desired polymers were achieved by doping with graphite to help lower the resistivity of the polymers thus increasing their conductivities. Graphite is an allotrope of carbon, others being diamond and fullerene. It is derived from the Greek word "Graphein", which means "to write and relates to the use of graphite for writing and drawing particularly pencils ${ }^{[3]}$. As a result of the nature of its bonding, graphite exhibits anisotropic properties thus graphite is highly electrically conductive in the plane direction due to the delocalized electrons and poorly conductive perpendicular to the layers ( $\mathrm{c}$-axis), as a result of the weak interlayer van-der waals forces ${ }^{[4]}$.Hence the doping process is the introduction of very small amounts of impurities example graphite that have more (ntype) or fewer (p-type) valence electrons to increase the conductivity of a semiconductor ${ }^{[5]}$.

\section{Materials and Methods}

Polymers; polystyrene, polypropylene,polyethylene and nylon 66 were prepared by doping them with graphite to enhance the electrical and thermal conductivity,considering the fact that they are of different intrinsic properties. The changes and differences in the rate of increase in electrical and thermal conductivities of the polymers were also reported. No neglect was also given to the opposite influence of the dopant on the electrical and thermal conductivities. 
All the materials and equipment used for this particular research were sourced from the chemistry and physics research Lab of the Nnamdi Azikiwe University Awka, Cutix Cable Nnewi, Relief Market Onitsha and electronic shops in Onitsha.

White brittle pack used for protecting electronic gadgets which is pure polystyrene, Non coloured sachet water carrier bag which is poly ethylene, Non colored rice sack which is polypropylene, White socks precisely 'Best Man' make which is pure nylon 66, Graphite from dry cell batteries . Electrical weighing balance from mettler Toledo 2007 mode serial no 021-64852350 ENGLAND, Stirring rods, Beakers (PYREX).Electrothermal Heater of about $250^{\circ} \mathrm{c}$ from Barnstaed 2006 model, serial no 10714483 England, Thermometer $-360^{\circ} \mathrm{C}$ thermometer, Wooden mould, Karthrometer, 500 mega ohms MASTECH multimeter No. 005-1349.

$5 \mathrm{~g}$ of the polymer were weighed into a $250 \mathrm{ml}$ beaker and heated at a regulated temperature of $130^{\circ} \mathrm{C}-250^{\circ} \mathrm{Cto}$ melt it using a thermometer and on continuous stirring to maintain a uniform temperature. During the process care was taken not to allow degradation. The dopant of known different percentage concentrations $0.00,0.05$, $0.10,0.50,0.75,1.00,1.25,1.50$ was added into the beaker containing the polymer and the two mixed thoroughly while heating respectively. The mixture was then poured immediately into the mould.

For each of the polymers; polypropylene, polyethylene, polystyrene and nylon 66 eight different percentage concentration $0.00,0.05,0.10,0.75,1.00,1.25,1.50$ of each of the dopants were introduced and their tablets formed. Their electrical and thermal conductivities were measured using 500 mega ohms MASTECH multimeter No. 005-1349 and Kathrometerrespectively.

\section{Results\&Discussion}

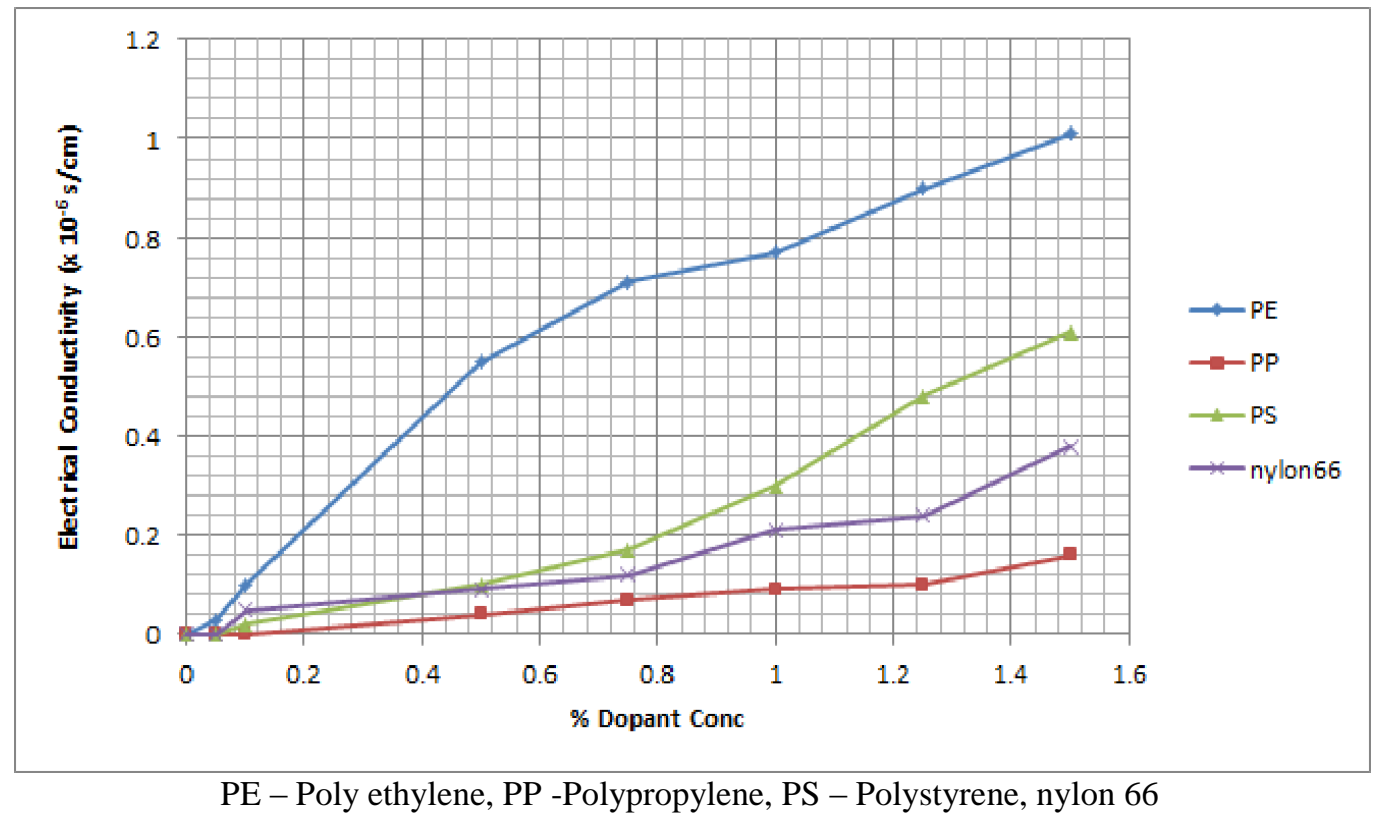

Figure 1: Effects of doping with graphite on the electrical conductivity of PE, PP, PS and nylon66

Fig. 1 Showed that the effect of doping with graphite enhanced electrical conductivities in this order: polyethylene<polystyrene<nylon 66< polypropylene. This is probably due to the order of amorphousness; polyethylene being most amorphous in nature with short branches showed the highest increment of the four polymers. It was also found that the electrical conductivity increases with increased dopant concentration in all the four polymers. This could be accounted for by the increasing "ISLAND OF GRAPHITE" as the concentration of graphite increases. The existence of island was also controlled by disorder in the molecular arrangement of the starting material and homogeneity of the doping process. It was also observed that this increase in the electrical conductivity with increasing dopant concentration was most marked with polyethylene and also followed the same trend as the degree of crystallinity to polystyrene which showed more increment than nylon 66 and polypropylene showed the least increment. 


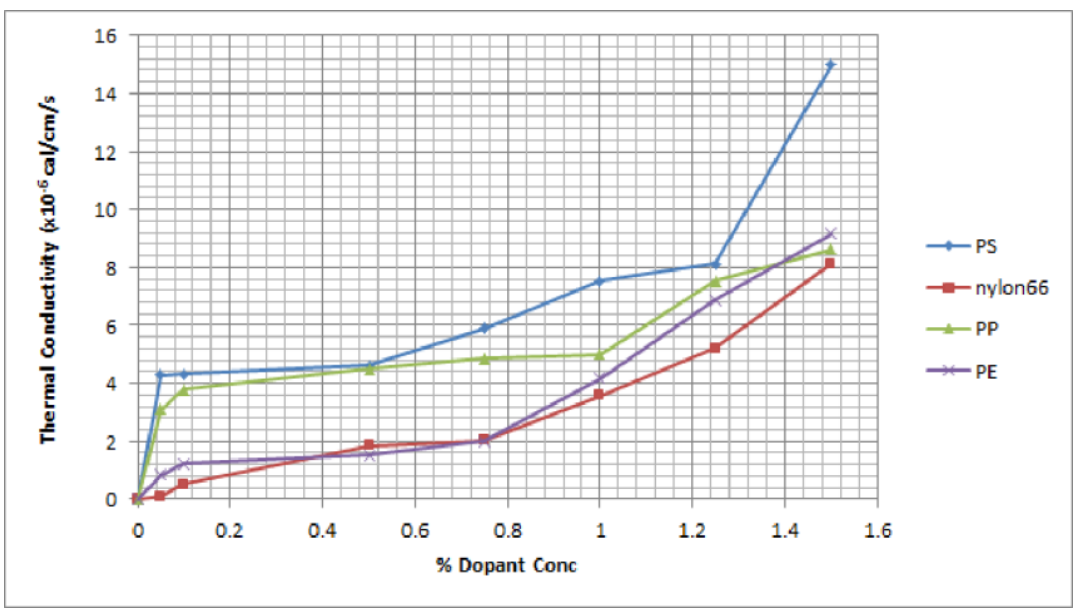

PE - Poly ethylene, PP -Polypropylene, PS - Polystyrene, nylon 66

\section{Figure 2: Effect of Doping with Graphite on the Thermal Conductivities of PS, nylon66, PP and \\ PE}

Fig 2 showed the effects of doping with graphite on the thermal conductivities of the polymers. Polystyrene performed best followed by polypropylene. There was also the spiking that resulted from increased conductivity at lower concentration which disappeared at a concentration of about $0.05 \mathrm{wt}$ percent as evident in polypropylene and $1.25 \mathrm{wt}$ percent in polystyrene, $0.75 \mathrm{wt}$ percent in nylon 66 and polyethylene. This spike could probably be as a result of increased organization or compactness provided by increased concentration of graphite, which increased heat transfer via photon. The lower concentration spike could be accounted for byelectron movements while the higher concentration spike could be accounted for by elastic wave like transfer of heats (photons) through the increased compact structure provided by the graphite and direct transfer of energy from one atom to another. Polyethylene because of its amorphousnessalso performed poorest but exhibited a spiking from $0.75 \mathrm{wt} \%$ accounted for by theincrease in its structural organization through the contribution of hexagonal arrangement of graphite molecules. The behavior of polystyrene which was very outstanding couldprobably be as a result of di-polarity improvement which made a negligible contribution to the thermal conductivity of its parent form but could be said to have made significant contribution to the thermal conductivity of the doped polystyrene due to its interaction with delocalized electron in the graphite. At higher concentration, the second spike could be from an increased compactness resulting from hexagonal arrangement of the graphite molecules. nylon66; has a crystalline structure whose inter-atomic integrity depends on the polar$\mathrm{CO}-\mathrm{NH}$ - side chain. The free electron in graphite could have interacted with the -CO-NH- in such a way that the inter atomic forces that determine the compactness of the crystalline structure of nylon 66 was broken therefore disrupting the ease with which energy was transferred from one atom of the polymer to the other thus making nylon 66 a poorer thermal conductor contrary to expectation from its crystalline form.

\section{Conclusion}

The four polymers doped had different degrees of enhancement in their electrical and thermal conduction. It was discovered that the electrical conductivity could vary directly with amorphousness of the polymer and inversely with crystallinity while the reverse was the case in thermal conductivity. These variations were seen to be not only dependent on them but also on the intrinsic properties of the polymers such as the dielectric and dipolar polarization of polystyrene. The - $\mathrm{CO}-\mathrm{NH}$ - polar group in nylon 66 contributed to various modifications in their behavior.

The work made it evident that commonly found conductive polymers can be used to do the work of semiconductors when doped although work need be done to bring them to the different required conductivities before employed in industrial use.

\section{References}

[1]. MacDiarmid A.G, Conductive polymer,Epstein American Journal Synthetic metal (65), 1994,103

[2]. Dahman.S.J ,synthesis ,characterization and application of inherently conducting polymers, Journal of polymer engineering and science vol. $39,1999,11$

[3]. Chung D .L, Graphite,Journal of material Science, 37(8), 2002, 1475 - 1489.

[4]. Pierson H.O, Handbook of Carbon, Graphite, Diamond and Fullerene : properties, processing and applications, (Noyes Publications Park Ridge, New Jersey, U.S.A ,1993)

[5]. Brown L.T, Lemay E.H,Jr., Brusten .E.B, Chemistry, The central science, modern materials 11ed.( Prentice-Hall Inc.,2009)

[6]. Wanekaya A.K, Lei.Y, Bekyarova .E., Chen.W., Haddon .R., fabrication and properties of conducting polypyrrole, Electroanalysis 18, No 11. ( wiley publishers wiley-VCH weinhem U.S.A., 2006) 1047-1054 
[7]. Noel .S., Hush .N., Ann .Y.,An Overview of the First Half Century of Molecular Electronic vol. 1006, (Academic Science Inc. New York, 2003) 1 - 20

[8]. Feast W.J, Synthesis of conducting polymers, in Skotheim T.A (ed), Hand book of Conductive polymers, 1(Marcel Dekker ,Inc. New York,1999) 1-2

[9]. Monikaa R.K,Synthesis of conducting polymers and their characterization, Indian Journal of Pure and Applied Physics. vol.48,July2010, 524

[10]. Bing R. H, Yen W., Semiconducting Polymers Applications Properties and Synthesis,American Chemistry Society vol.735 ,1999 